Check for updates

Cite this: RSC Adv., 2017, 7, 46615

\title{
Two-photon controlled sol-gel condensation for the microfabrication of silica based microstructures. The role of photoacids and photobases $\uparrow$
}

\author{
J. Kustra, ${ }^{\text {ab }}$ E. Martin, ${ }^{a}$ D. Chateau, ${ }^{a}$ F. Lerouge, ${ }^{a}$ C. Monnereau, (D) a C. Andraud, ${ }^{a}$ \\ M. Sitarz, ${ }^{b}$ P. L. Baldeck ${ }^{a}$ and S. Parola (iD *a
}

Received 3rd August 2017

Accepted 27th September 2017

DOI: $10.1039 / \mathrm{c} 7 \mathrm{ra0} 8608 \mathrm{c}$

rsc.li/rsc-advances

\begin{abstract}
Two-photon excitation of photobases is used to induce $\mathrm{pH}$ changes and control the condensation step of the sol-gel process at the focal point of a laser beam in a confocal configuration. This two-photon microfabrication process, which is usually used in the polymerization of organic monomers, enables the generation of 2D and 3D inorganic Si-O-Si networks of silica based materials with micron resolution. Different variables for the formulation are studied, including the mechanism of condensation, the type of photo initiator, the solvent and the concentration used, as well as the laser parameters.
\end{abstract}

\section{Introduction}

Two-photon polymerization was developed in the late 90s for the fabrication of three dimensional microstructures using photo-sensitive formulations and it was mostly applied initially to polymeric organic systems. ${ }^{1-3}$ This fabrication technique permits high resolution $3 \mathrm{D}$ fabrication thanks to the twophoton optical process, which allows highly localized control of the photo-induced reactions in the focal point region of the laser. Regarding inorganic and hybrid materials, the first works reported the use of inorganic-organic hybrid resins that underwent radical polymerization when exposed to irradiation. These resins incorporated silica precursors that built up hybrid interpenetrating networks. Two-photon polymerized ORMOCERS were introduced with structure sizes of $200 \mathrm{~nm} .{ }^{4}$ Later on, those strategies were extended to $\mathrm{Zr}-\mathrm{Si}$ based oxide materials, ${ }^{5}$ SiCN nanostructures, ${ }^{6}$ or $\mathrm{TiO}_{2}$ patterning. ${ }^{7,8}$ In all these examples, the control of the microstructure was performed via twophoton induced polymerization reactions and the polymeric organic network was used as template for the structuration. The inorganic reaction was separately produced via for instance hydrolysis of metal-organic precursors. The organic part can then be removed and reveal the inorganic microstructure. It is interesting to note the possibility of using two-photon excitation for lithography techniques. For instance lasers are used to

${ }^{a}$ Laboratoire de Chimie, Ecole Normale Supérieure de Lyon, CNRS, Université Claude Bernard Lyon 1, UMR 5182, 46 allée d'Italie, 69364, Lyon, France. E-mail: stephane. parola@ens-lyon.fr

${ }^{b}$ AGH University of Science and Technology, Faculty of Materials Science and Ceramics, Mickiewicza 30, 30-059 Cracow, Poland

$\dagger$ Electronic supplementary information (ESI) available. See DOI: 10.1039/c7ra08608c produce 3D photonic crystals in chalcogenides photosensitive glasses. ${ }^{9}$ Similarly microstructured ceramics are obtained by preparing a 3D polymer scaffold by two-photon microlithography followed by alumina deposition, ion beam milling and plasma etching. ${ }^{10}$

In our work we investigate a method allowing two-photon absorption control of the condensation step of silicon based pre-hydrolyzed precursors in the sol-gel process towards microstructured inorganic silica based networks. The process occurs in two sequences. The first step is the preparation of a stable silica sol through the controlled hydrolysis of silicon alkoxide precursors (MTEOS - methyltriethoxysilane) in acidic conditions (HCL). This generates stable and homogeneous suspension of silica-based oligomers. In the usual sol-gel process, the second step, namely the condensation reactions of these oligomers, is controlled by a $\mathrm{pH}$ change through addition of a base or acid in order to fulfill the inorganic polymerization. We report here the possibility to control this inorganic polymerization by tuning locally the $\mathrm{pH}$ with photo-acids and photobases. Such molecular entities express interesting potential $\mathrm{pH}$ changes under laser excitation, in particular using twophoton process. The $\mathrm{pH}$ change occurs then exclusively in the focal point of the laser. Thus, the condensation is photochemically induced exclusively in the volume of the focus of the laser beam. 3D micro-fabrication can then be achieved by simply controlling the displacement of the focal point. Finally the substrate is immersed in an appropriate solvent for washing and elimination of the sol part that has not been irradiated. In this paper we report the investigation on the role of the photosensitizer, the solvent and concentrations on the sol-gel condensation process and, to the best of our knowledge, the first two-photon controlled sol-gel condensation reaction. 


\section{Results and discussion}

The sol-gel condensation steps on silica-based materials can be controlled using either basic or acid catalysis. Taking this background in consideration the use of photo-induced $\mathrm{pH}$ changes can be a trend to control condensation reaction with light. Moreover such photo-induced local $\mathrm{pH}$ changes can be driven either with common one-photon or two-photon excitation. Two-photon excitation provides a means for activating the polymerization of the silica oligomers with higher $3 \mathrm{D}$ resolution than that of normal excitation. However, this requires the use of optimized molecular structures as initiators of the chemical reaction.

\section{Photosensitizers and control of the condensation catalysis}

The probability of two-photon absorption by the initiator molecules depends quadratically on the intensity of the laser and, consequently, it takes place within the very confined volume defined by the focal point. In order to induce the polymerisation reactions, the initiators must have large enough twophoton absorption cross-sections $(\delta)$. For most of the commercial compounds the two-photon cross-sections are small, usually below $1 \mathrm{GM}\left(10^{-50} \mathrm{~cm}^{4} \mathrm{~s}\right.$ per photon). Molecules having the general structural core $\mathrm{D}-\pi-\mathrm{D}, \mathrm{D}-\pi-\mathrm{A}-\pi-\mathrm{D}$ and $\mathrm{A}-\pi-\mathrm{D}-\pi-\mathrm{A}$ have relatively large $\delta$. This ability to absorb the two-photon increases with the conjugation length and the donor and acceptor strengths. The two-photon sensitivity depends on both the cross-section and the overall chemical efficiency of initiation. The evaluation of the two types of catalysis, acid and basic, for the condensation of a pre-hydrolysed silica sol is presented hereunder.

Hydrolysis of the sol. The sol is prepared starting from alkoxysilane precursors, typically glycidyloxypropyl)trimethoxysilane (GLYMO) or MTEOS, which are hydrolysed under acidic $\mathrm{pH}$ according to previously reported procedures. ${ }^{11-14}$ It is then mixed with the different photosensitizers in various ratios and concentrations to evaluate and optimize the fabrication process. Two types of photosensitizers are investigated, photoacids and photo-bases.

Acidic catalysis using photo-latent acid catalysts. In the solgel process, the second step related to the network formation of the oxides can be associated to protonated silanol intermediates. Fig. 1 shows the mechanism of condensation in acidic conditions. Usually this is achieved using mineral acids $(\mathrm{HCl}$, $\mathrm{HNO}_{3}$ ).

Two different photo-acid compounds, Irgacure ${ }^{\circledR} 250$ and triarylsulfonium hexafluorophosphate salts mixture with absorbance in the expected wavelengths range are used to try to induce the polymerization, sometimes with the addition of a photosensitizer to increase the probability of absorption

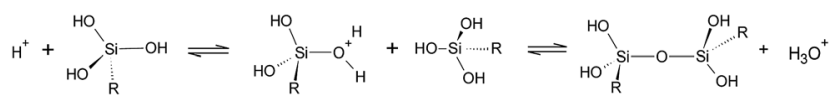

Fig. 1 Mechanism of sol-gel condensation under acid catalysis.
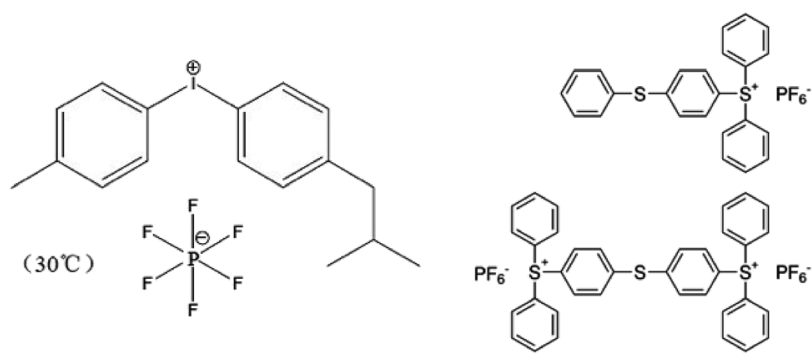

Fig. 2 Structure of the photo-acids used: Irgacure ${ }^{\circledR} 250$ (left, absorption peak in $\mathrm{MeOH}=242 \mathrm{~nm}$; the commercial solution was $75 \%$ in propylene carbonate); and triarylsulfonium hexafluorophosphate salts mixture (right, the commercial solution was $50 \%$ of compound in propylene carbonate).

Table 1 Example of compositions used in the Irgacure ${ }^{\circledR} 250$ systems (irradiation conditions: exposure time 5-20 ms, laser power $0.1-0.12 \mathrm{~V})$

\begin{tabular}{lll}
\hline & $\begin{array}{l}\text { Irgacure }{ }^{\circledR} 250 \\
\text { (ratio based on } \\
\text { total silane amount) }\end{array}$ & Anthracene \\
\hline $\begin{array}{l}0.25 \text { g MTEOS sol } \\
(30 \% \text { in THF })\end{array}$ & $5 \%$ & $1 \%$ \\
$\begin{array}{l}0.5 \text { g GLYMO sol } \\
(80 \% \text { in methanol })\end{array}$ & $5 \%$ & $1 \%$ \\
$\begin{array}{l}0.5 \text { g GLYMO sol } \\
(80 \% \text { in methanol })\end{array}$ & $10 \%$ & $1 \%+100 \mu \mathrm{L}$ propylene \\
& & $\begin{array}{l}\text { carbonate } \\
\end{array}$
\end{tabular}

(Fig. 2). Several ratios are evaluated in the case of Irgacure ${ }^{\circledR} 250$ as reported in Table 1.

No fabrication is observed in any of the cases using the Irgacure ${ }^{\circledR} 250$. The same observation is done when using triarylsulfonium hexafluorophosphate salts as a photo-acid in similar conditions. Indeed the use of such photo-acid is not in favour of condensation reaction but mostly in favour of the hydrolysis. In our case the hydrolysis ratio becomes extremely high, close to $100 \%$ but basic catalysis becomes necessary to induce the condensation step.

Basic catalysis using a photo-latent basic catalysts. In basic assisted condensation, the cross-linking starts at early stages in the process, and condensation rates are higher than in acid conditions (Fig. 3).

The role and efficiency of the photo-base is evaluated on different structures exhibiting either the photo-generation of hydroxyles $\mathrm{OH}-$, or amine derivatives. The photo-bases are $\mathrm{N}$ methylnifedipine derivative, tetramethylguanidine phenylglyoxylate $^{15}$ or 9-xanthenylmethyl $\mathrm{N}$-cyclohexylaminecarbamate.

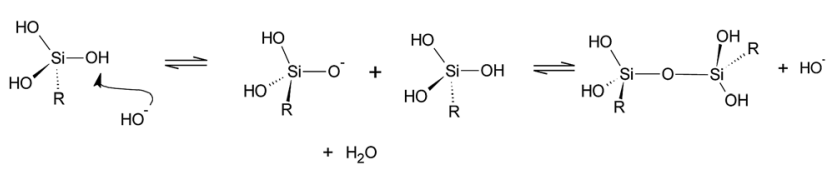

Fig. 3 Mechanism of sol-gel condensation catalysed by base. 




Scheme 1 Degradation of the $N$-methylnifedipine derivative when exposed to UV-visible radiation.

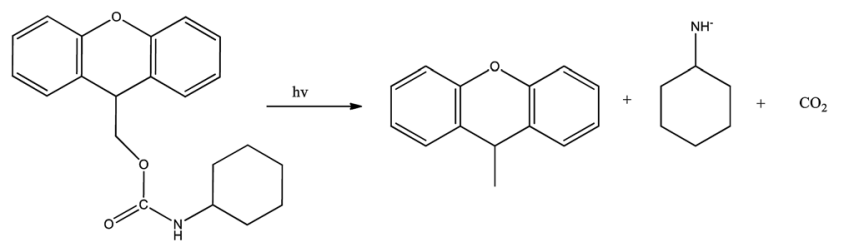

Scheme 2 Degradation of the 9-xanthenylmethyl $\mathrm{N}$-cyclohexylaminecarbamate photobase under laser exposure.

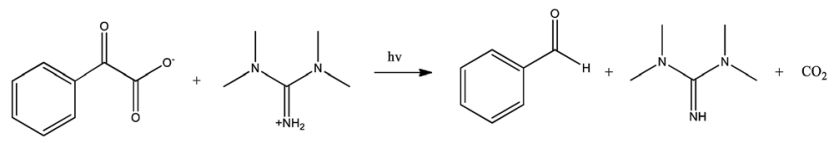

Scheme 3 Photo-induced reaction on the tetramethylguanidine phenylglyoxylate under laser exposure.

The mechanisms occurring under irradiation are reported in respectively Schemes 1-3. $N$-Methylnifedipine has been slightly modified replacing the original two methoxy groups for two ethoxy groups to increase solubility and stability. To the best of our knowledge, this is the only compound reported in the literature which is able to release an $\mathrm{OH}^{-}$group according to Scheme $1 .^{16}$

The role of the solvent and the photo-base concentration is investigated. The $\mathrm{pH}$ change during the process is evidenced by using $\mathrm{pH}$ paper, the photobase being insoluble in water, showing the stronger variation from 5 to 10 under UV irradiation (Fig. S1 $\dagger$ ). The experimental conditions are resumed in Table 2. In the case of sample 1; due to the high volatility of the THF (bp $=66{ }^{\circ} \mathrm{C}$ ), the sample evaporates quickly in our operating conditions (room temperature) inducing the recrystallization of the photo-base, and sometimes the solidification of

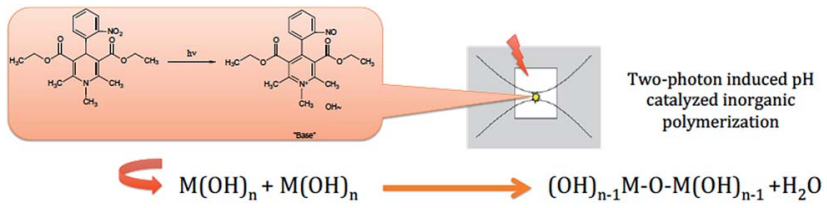

Fig. 4 Principe of microfabrication using $N$-methylnifedipine derivative as a photo-base.

the gel. Even so, polymerization can be provoked in some parts of the sample but cannot be washed afterwards. It can be improved by performing fast fabrication (sample 2), which allowed achieving the network (Fig. 5). However, the evaporation is still too fast and some of the sol tended to condensate around the performed structure prior to washing. Moreover, as it can be seen in the SEM images of Fig. 5, the drawn lines are of about $930 \mathrm{~nm}$ width, which is little larger than the focal point of the laser which is about $200 \mathrm{~nm}$. This is due to diffusion of the produced $\mathrm{pH}$ change slightly out of the focus region. We have thus decided to add solvent with higher boiling point to the formulation, the benzyl alcohol $\left(\mathrm{bp}=205^{\circ} \mathrm{C}\right.$ ).

Samples 3, in which benzyl alcohol is added in order to increase the boiling point of the solvent and slow down the evaporation, leads to photo-induced condensation but with low resolution and homogeneity (optical images Fig. S2 $\dagger$ ). In sample 4 and 5 the ratio of benzyl alcohol is increased. As observed on Fig. 6 and 7, the quality and resolution of the microfabrication is improved while increasing the benzyl alcohol amount. This can be explained by the better control of the solvent evaporation during the process allowing longer operating condition prior to the washing step. The profile of the fabrication shows much higher regularity and periodicity (Fig. 7 right). The line width remains however slightly larger than the focal point.

Interestingly, when increasing more the benzyl alcohol amount (sample 6), the fabrication is not observed anymore. This can be attributed to the higher dilution of the sol and photo-base preventing from possible condensation between oligomers. Same situation is observed when decreasing the concentration of the sol confirming this result (sample 7).

Two other types of known photo-bases, activated according the Schemes 2 and $3,{ }^{17}$ are experimented in order to identify the mechanism involved in the condensation of the silica network.

Table 2 Experimental conditions used with $\mathrm{N}$-methylnifedipine (irradiation conditions: 0.07-0.09 V, exposure time $10 \mathrm{~ms}$ )

\begin{tabular}{|c|c|c|c|c|}
\hline Sample & Sol & Photobase & Solvent & Microfabrication \\
\hline 1 & $0.25 \mathrm{~g}$ MTEOS sol $[30 \mathrm{wt} \%$ in THF] & $17 \mathrm{mg} N$-methylnifedipine & $0.5 \mathrm{~mL}$ THF & Not controlled \\
\hline 2 & $0.25 \mathrm{~g}$ MTEOS sol $[30 \mathrm{wt} \%$ in $\mathrm{THF}]$ & $17 \mathrm{mg} N$-methylnifedipine & $0.5 \mathrm{~mL}$ THF & $\begin{array}{l}\text { Unstable in time } \\
\text { and low control }\end{array}$ \\
\hline 3 & $0.25 \mathrm{~g}$ MTEOS $[30 \mathrm{wt} \%$ in $\mathrm{THF}]$ & $17 \mathrm{mg} N$-methylnifedipine & $0.5 \mathrm{~mL}$ THF $+50 \mu \mathrm{L}$ benzylalcohol & Poor control \\
\hline 4 & $0.25 \mathrm{~g}$ MTEOS [30 wt\% in THF] & $17 \mathrm{mg} N$-methylnifedipine & $0.5 \mathrm{~mL}$ THF $+69 \mu \mathrm{L}$ benzylalcohol & Good control \\
\hline 5 & $0.25 \mathrm{~g}$ MTEOS $[30 \mathrm{wt} \%$ in $\mathrm{THF}]$ & $17 \mathrm{mg} N$-methylnifedipine & $0.5 \mathrm{~mL}$ THF $+83 \mu \mathrm{L}$ benzylalcohol & Good control \\
\hline 6 & $0.25 \mathrm{~g}$ MTEOS $[30 \mathrm{wt} \%$ in $\mathrm{THF}]$ & $17 \mathrm{mg} N$-methylnifedipine & $0.5 \mathrm{~mL}$ THF $+165 \mu \mathrm{L}$ benzylalcohol & No fabrication, too diluted \\
\hline 7 similar to 5 & $0.15 \mathrm{~g}$ MTEOS $[30 \mathrm{wt} \%$ in THF] & $11 \mathrm{mg} N$-methylnifedipine & $0.25 \mathrm{~mL}$ THF $+65 \mu \mathrm{L}$ benzylalcohol & Good control \\
\hline
\end{tabular}




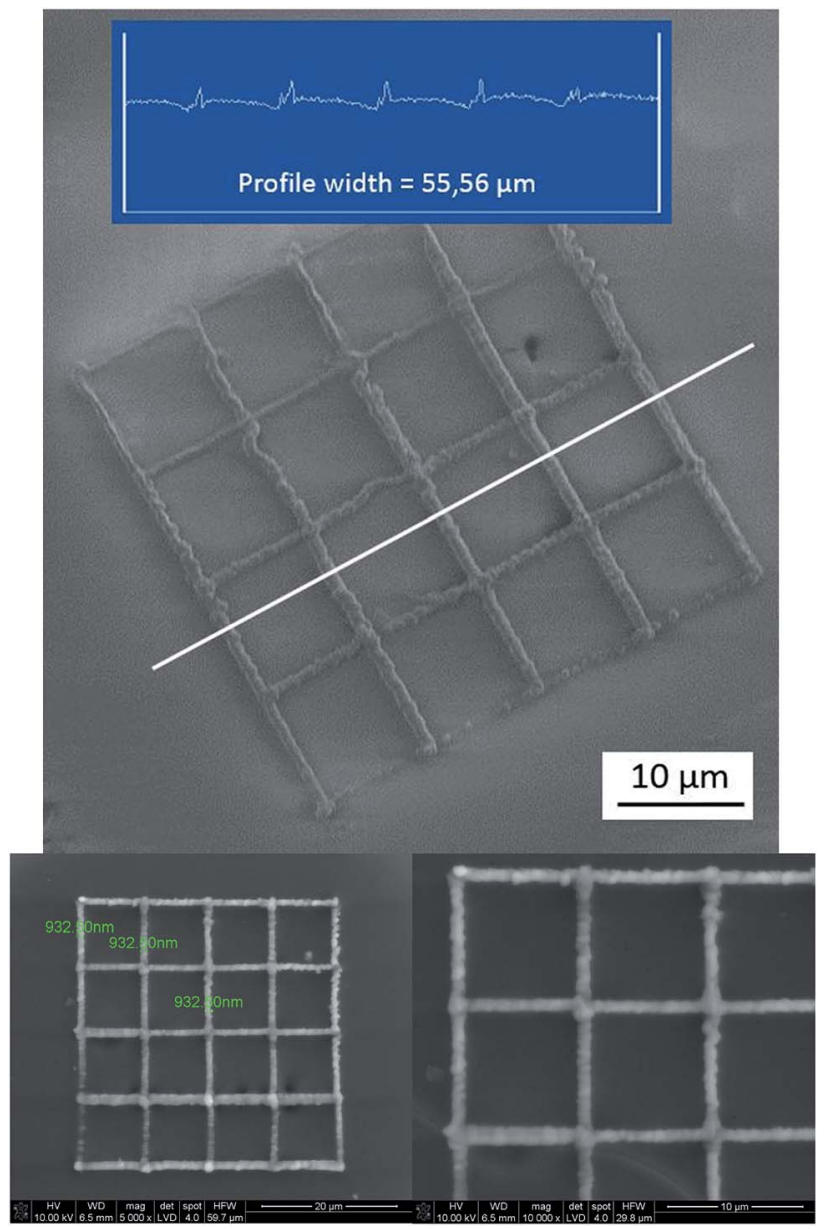

Fig. 5 SEM images of networks fabricated with sample 2 procedure. The topological profile is inserted in the top image.

No fabrication is obtained in both cases. This evidences the key role of the $\mathrm{OH}^{-}$entities in the mechanism of basic catalysis in this derived photoinduced sol-gel process (Fig. 3 and 4).

\section{Fabrication of 3D microstructures}

The synthetized $N$-methylnifedipine derivative proved to have the best chemical efficiency to induce a complete condensation

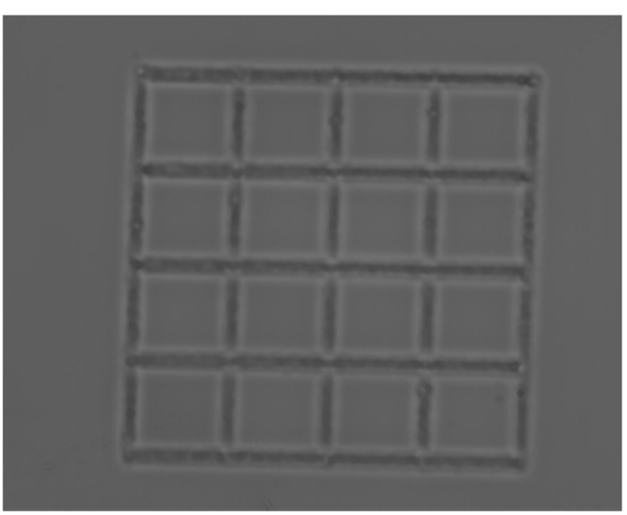

Fig. 6 Optical images of microfabrication using conditions of sample 4 (10 $\mu \mathrm{m}$ between two drawn lines).

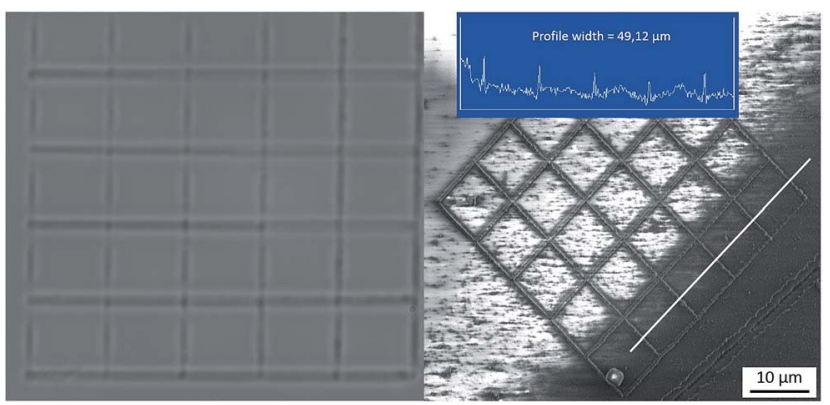

Fig. 7 Microfabrication using the conditions of sample 5, optical (left, $10 \mu \mathrm{m}$ between two drawn lines) and SEM (right) images. Inserted in the SEM image: profile of the material.
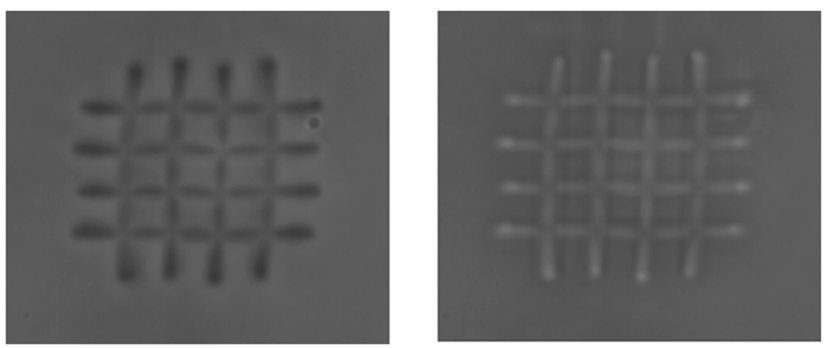

Fig. 8 Upper (left) and lower (right) planes of a 3D prepared woodpile structure.

in the focal point and fabricate structures resistant to the washing process. The addition of co-solvents to the formulation turns out to be a setback for the oligomers bonding to form a 3D network, while the use of a volatile solvent like THF allows for the fabrication in the bulk of the sample. The use of the formulation 2 previously discussed successfully leads to $3 \mathrm{D}$ microstructures of $8 \mu \mathrm{m}$ high, calculated approximately from the confocal microscope graduation (Fig. 8).

Such 3D structures show lower resolution than 2D structures due to a longer time processing, allowing the base diffusion outside of the focal point. Further work is ongoing in our laboratory in order to prevent the base diffusion by decreasing the solvent amount or increasing the fabrication speed.

\section{Experimental}

Irgacure ${ }^{\circledR} 250$ is provided by the BASF company, triarylsulfonium hexafluorophosphate was bought from Aldrich. Tetramethylguanidine phenylglyoxylate and $N$-methylnifedipine derivative are prepared according to the procedure described in the literature. ${ }^{15,16}$

\section{Preparation of the hydrolysed sol}

Trifunctional organosilane compound methyltriethoxysilane (MTEOS) possess three hydrolysable ethoxy groups $\left(\mathrm{OC}_{2} \mathrm{H}_{5}\right)$ and one non-hydrolysable methyl group $\left(\mathrm{CH}_{3}\right)$. In the first step of the process a $60 \mathrm{~mL}$ of MTES precursor and $70 \mathrm{~mL}$ of water $(\mathrm{pH}=$ $3.5, \mathrm{HCl})$ are combined in $250 \mathrm{~mL}$ flask. The mixture is stirred 
for 45 min until a homogeneous transparent mixture is obtained. The obtained sol is heated in an oil bath to $130{ }^{\circ} \mathrm{C}$ and ethanol is removed by distillation. When around $60-70 \mathrm{~mL}$ of ethanol has been distilled, the sol becomes turbid: it is then removed from the oil bath and directly cooled down using $100 \mathrm{~mL}$ of ice-cold water. Afterwards, the water is removed by decantation, and diethylether is added to dilute the sol. More water is removed after phase separation and the sol is filtered using syringe filter $(0.45 \mu \mathrm{m})$. Finally, a solvent exchange is undertaken by evaporation of the remaining diethyl ether and addition of proper solvent (THF) to obtain a $30 \mathrm{wt} \%$ solution. The resulting sol is stable for long time storage preferably at low temperature $\left(-19^{\circ} \mathrm{C}\right)$.

\section{Synthesis of $N$-methylnifedipine ethyl ester derivative}

In a $20 \mathrm{~mL}$ screw cap glass flask containing a magnetic stirrer, $1.51 \mathrm{~g}$ (10 mmol) of 2-nitrobenzaldehyde dissolved in $2.86 \mathrm{~g}$ $(22 \mathrm{mmol})$ of ethylacetoacetate are introduced, followed by $0.73 \mathrm{~g}$ of methylamine hydrochloride $(12 \mathrm{mmol})$ and $1 \mathrm{~mL}$ of pyridine. The flask is closed and heated at $85{ }^{\circ} \mathrm{C}$ in an oil bath under stirring for $8 \mathrm{~h}$. Afterwards, the mixture is diluted with $20 \mathrm{~mL}$ of $\mathrm{MeOH} / \mathrm{H}_{2} \mathrm{O}(90: 10)$ and put at $5{ }^{\circ} \mathrm{C}$ overnight. After filtration on büchner and careful washing with $3 \times 10 \mathrm{~mL}$ cold $\mathrm{MeOH} / \mathrm{H}_{2} \mathrm{O}$ ( 90 : 10) mixture and $2 \times 20 \mathrm{~mL} \mathrm{H}_{2} \mathrm{O}$, the product (yellow crystals) is dried at $45{ }^{\circ} \mathrm{C}$ for 2 hours. $2.01 \mathrm{~g}$ of $\mathrm{N}$-methylnifedipine ethyl ester derivative are obtained (yield: $52 \%$ ).

${ }^{1} \mathrm{H}-\mathrm{NMR}$ spectrum (solvent: $\mathrm{CDCl}_{3}$ ): 1.25 (t, $6 \mathrm{H}, \mathrm{CH}_{3}$ ethyl), 2.45 (s, 6H, methyl), 3.28 (s, 3H, $N$-methyl), 4.14 (dq, $4 \mathrm{H}, \mathrm{CH}_{2}$ ethyl), 5.77 (s, 1H, CH), 7.2-7.7 (m, $4 \mathrm{H}$, aromatic $\mathrm{CH})$.

\section{Synthesis of the 9-xanthenylmethyl $\mathrm{N}$ - cyclohexylaminecarbamate}

The synthesis of 9-xanthenylmethyl $N$-cyclohexylaminecarbamate is adapted from the synthetic route previously reported by $\mathrm{Du}$ et al. and requires the synthesis of two intermediates (Fig. 9) ${ }^{18}$

Synthesis of xanthene-9-ethanol. A solution of $\mathrm{LiAlH}_{4}(0.43 \mathrm{~g}$, $11.4 \mathrm{mmol}, 1.3$ eq.) in anhydrous $\mathrm{Et}_{2} \mathrm{O}(15.5 \mathrm{~mL})$ is placed in two-necked flask equipped with reflux condenser and dropping funnel is stirred at RT. To this solution, is added xanthene-9carboxylic acid (1.988 g, $8.79 \mathrm{mmol}, 1$ eq.) gently and $\mathrm{Et}_{2} \mathrm{O}$ anhydrous $(14 \mathrm{~mL})$ dropwise together to produce gentle reflux.

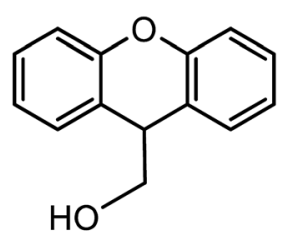

(a)

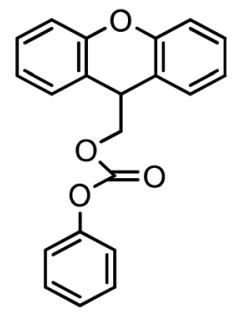

(b)



(c)
Fig. 9 Structures of the xanthene-9-ethanol intermediate (a), 9xanthenylmethyl phenylcarbonate intermediate (b), and 9-xanthenylmethyl $\mathrm{N}$-cyclohexylaminecarbamate (c).
The mixture is stirred under argon at RT for $1 \mathrm{~h} . \mathrm{H}_{2} \mathrm{O}$ is added cautiously by cooling the mixture with ice-water bath before adding $10 \%$ of $\mathrm{H}_{2} \mathrm{SO}_{4}(10 \mathrm{~mL})$ and $20 \mathrm{~mL}$ of AcOEt to decompose the excess of $\mathrm{LiAlH}_{4}$ and xanthene-9-carboxylic acid, resulting in a grey suspension. The mixture is partitioned between AcOEt and $\mathrm{H}_{2} \mathrm{O}$. The aqueous phase is extracted with AcOEt $(30 \mathrm{~mL} \times 3)$. The reunited organic phase is washed with $\mathrm{H}_{2} \mathrm{O}(30 \mathrm{~mL} \times 1)$, dried over $\mathrm{Na}_{2} \mathrm{SO}_{4}$ and concentrated under vacuum to obtain a white powder $(1.694 \mathrm{~g}, 91 \%)$.

${ }^{1} \mathrm{H}-\mathrm{NMR}\left(300 \mathrm{MHz}, \mathrm{CDCl}_{3}, 298 \mathrm{~K}\right) \delta 7.31 \mathrm{ppm}(\mathrm{m}, 4 \mathrm{H}, \mathrm{H})$, $7.11 \mathrm{ppm}(\mathrm{m}, 4 \mathrm{H}, \mathrm{H}), 4.04 \mathrm{ppm}(\mathrm{t}, J=6.32 \mathrm{~Hz}, \mathrm{H}), 3.66 \mathrm{ppm}(\mathrm{d}$, $J=6.23 \mathrm{~Hz}, 2 \mathrm{H}, \mathrm{CH}_{2}$ ).

Synthesis of 9-xanthenylmethyl phenylcarbonate. Xanthene9-ethanol (1.49 g, $7.02 \mathrm{mmol}, 1$ eq.) is dissolved with DCM $(6.76 \mathrm{~mL})$. The solution is placed in a monocol equipped with magnetic stirrer. Pyridine $(0.85 \mathrm{~mL})$ is added dropwise. The mixture is stirred and bubbled under argon for approximately $5 \mathrm{~min}$. To this solution, was added phenyl chloroformate (1.33 mL, $10.6 \mathrm{mmol}, 1.5$ eq.) dropwise to form a yellow solution. The mixture is stirred under argon at RT for $2 \mathrm{~h}$. $10 \%$ of $\mathrm{H}_{2} \mathrm{SO}_{4}(10 \mathrm{~mL})$ is added cautiously to the mixture followed by $20 \mathrm{~mL}$ of DCM to eliminate the excess of phenyl chloroformate and protonate the pyridine. The mixture is partitioned between DCM and $\mathrm{H}_{2} \mathrm{O}$. The aqueous phase is extracted with DCM $(30 \mathrm{~mL} \times 3)$. The reunited organic phase is washed with $\mathrm{H}_{2} \mathrm{O}$ acidic $(30 \mathrm{~mL} \times 1)$, dried over $\mathrm{Na}_{2} \mathrm{SO}_{4}$ and concentrated under vacuum to give a pink-orange powder $(1.20 \mathrm{~g}, 52 \%)$.

${ }^{1} \mathrm{H}-\mathrm{NMR}\left(300 \mathrm{MHz}, \mathrm{CDCl}_{3}, 298 \mathrm{~K}\right) \delta 7.30-6.81 \mathrm{ppm}(\mathrm{m}, 13 \mathrm{H}$, $\mathrm{H}$ aromatiques), $4.33 \mathrm{ppm}(\mathrm{s}, 3 \mathrm{H})$.

Synthesis of 9-xanthenylmethyl $\mathrm{N}$-cyclohexylaminecarbamate. A solution of xanthenes-9-phenylcarbonate $(0.500 \mathrm{~g}, 1.510 \mathrm{mmol}, 1$ eq.) in DMF $(7.08 \mathrm{~mL})$ is placed in a microwave tube and stirred under argon at RT. A solution of cyclohexylamine $(0.19 \mathrm{~mL}$, $1.650 \mathrm{mmol}, 1.2$ eq.) in DMF $(2.40 \mathrm{~mL})$ is added dropwise by syringe into the mixture and stirred under argon at RT for additional $5 \mathrm{~min}$. The microwave tube is then put inside the microwave and the reaction is set at $50{ }^{\circ} \mathrm{C}$ for $12 \mathrm{~h}$ (overnight). $\mathrm{H}_{2} \mathrm{O}(20 \mathrm{~mL})$ is added. The mixture is partitioned between $\mathrm{H}_{2} \mathrm{O}$ and diethyl ether. The aqueous layer is extracted with diethyl ether $(20 \mathrm{~mL} \times 3)$. The reunited organic phase is dried over $\mathrm{Na}_{2} \mathrm{SO}_{4}$ and concentrated under vacuum resulting in a white pasty powder $(0.443 \mathrm{~g}, 95 \%)$.

${ }^{1} \mathrm{H}-\mathrm{NMR}\left(300 \mathrm{MHz}, \mathrm{CDCl}_{3}, 298 \mathrm{~K}\right) \delta 7.30-7.20 \mathrm{ppm}(\mathrm{m}, 6 \mathrm{H})$, $6.86 \mathrm{ppm}(\mathrm{m}, 4 \mathrm{H}), 4.30 \mathrm{ppm}(\mathrm{t}, J=6.02 \mathrm{~Hz}, 1 \mathrm{H}, \mathrm{H}), 4.20 \mathrm{ppm}(\mathrm{d}$, $\left.J=6.04 \mathrm{~Hz}, 2 \mathrm{H}, \mathrm{CH}_{2}\right), 1.73-1.30 \mathrm{ppm}(\mathrm{m}, 10 \mathrm{H})$.

\section{Two-photon polymerisation set-up and process}

Two-photon polymerisation tests are realized with a high resolution 3D micro-printing machine (http://www.microlight.fr/). It is based on an inverted microscope, a microchip laser, and a $3 \mathrm{D}$ nano-positioning piezo-stage (PZT). The self-Q switched microchip laser generates sub-nanosecond pulses at $532 \mathrm{~nm}$ with a $10 \mathrm{kHz}$ repetition rate, and a maximum average power of $20 \mathrm{~mW}$. The laser is focalized in the resin with a high numerical aperture microscope $(\mathrm{NA}=1.4)$ providing a laser spot of about 0.2 micron (FWHM). 
The sample are deposited on $24 \times 24 \mathrm{~mm}^{2}$ cover glass plate after an alkalinisation treatment by scrubbing its surface with a $\mathrm{KOH}$ solution $20 \%$ in ethanol/water. DI water is used to rinse the surface and remove the excess of base. A $15 \mu \mathrm{L}$ droplet of photosensitive liquid material is deposited on to the surface of the glass substrate. The laser focus is set in the resin at the upper the glass surface. Line fabrication are obtained by PZT scanning the sample with a speed of 100 micron per s, and a laser power in the range of $1 \mathrm{~mW}$ (measured before the microscope objective). The non-polymerised material is removed by rinsing and immersing the glass substrate in ethanol for 2 minutes.

\section{Conclusions}

Two-photon induced $\mathrm{pH}$ changes are used to control inorganic condensation process during the sol-gel microfabrication of $2 \mathrm{D} /$ 3D structures of silica based materials. The role of the most important parameters is investigated, typically the structure of the photobase, the concentrations, the solvent. The amount of photoinitiator in the sample needs to be significant enough to induce the inorganic polymerization. On the other hand, very high concentrations of photocatalyst lead to non-desired condensation out of the focal point and thus a loss in the resolution. This extends the concept of two-photon 3D micro-fabrication oftently used on organic polymerization reactions toward the control of inorganic polymerization and possibilities to directly fabricate hybrid and inorganic materials. The potentiality to further easily design microceramics using laser with submicronic resolution open tremendous perspectives in fields such as photonic crystals, optoelectronic devices, sensors. This work is ongoing in our laboratory and will be the topic of next reports.

\section{Conflicts of interest}

There are no conflict to declare.

\section{Acknowledgements}

PULSALYS and ENS are acknowledged for funding.

\section{Notes and references}

1 S. Maruo, O. Nakamura and S. Kawata, Opt. Lett., 1997, 22(2), 132.

2 B. H. Cumpston, S. P. Ananthavel, S. Barlow, D. L. Dyer, J. E. Ehrlich, L. L. Erskine, L. Lael, A. A. Heikal,
S. M. Kuebler, I. Y. S. Lee, D. McCord-Maughon, J. Qin, H. Röckel, M. Rumi, X.-L. Wu, S. R. Marder and J. W. Perry, Nature, 1999, 398(6722), 51.

3 I. Wang, M. Bouriau, P. L. Baldeck, C. Martineau and C. Andraud, Opt. Lett., 2002, 27(15), 1348.

4 J. Serbin, A. Egbert, A. Ostendorf, B. N. Chichkov, R. Houbertz, G. Domann, J. Schulz, C. Cronauer, L. Fröhlich and M. Popall, Opt. Lett., 2003, 28(5), 301.

5 A. Ovsianikov, J. Viertl, B. Chichkov, M. Oubaha, B. MacCraith, I. Sakellari, A. Giakoumaki, D. Gray, M. Vamvakaki, M. Farsari and C. Fotakis, ACS Nano, 2008, 2(11), 2257.

6 T. A. Pham, D. P. Kim, T. W. Lim, S. H. Park, D. Y. Yang and K. S. Lee, Adv. Funct. Mater., 2006, 16(9), 1235.

7 S. Passinger, M. S. Saifullah, C. Reinhardt, K. R. Subramanian, B. N. Chichkov and M. E. Welland, Adv. Mater., 2007, 19(9), 1218.

8 I. Sakellari, A. Gaidukeviciute, A. Giakoumaki, D. Gray, C. Fotakis, M. Farsari, M. Vamvakaki, C. Reinhardt, A. Ovsianikov and B. N. Chichkov, Appl. Phys. A: Mater. Sci. Process., 2010, 100(2), 359.

9 S. Wong, M. Deubel, F. Pérez-Willard, S. John, G. A. Ozin, M. Wegener and G. von Freymann, Adv. Mater., 2006, 18(3), 265.

10 L. R. Meza, S. Das and J. R. Greer, Science, 2014, 345(6202), 1322.

11 D. Chateau, F. Chaput, C. Lopes, M. Lindgren, C. Brännlund, J. Öhgren, N. Djourelov, P. Nedelec, C. Desroches, B. Eliasson, T. Kindahl, F. Lerouge, C. Andraud and S. Parola, ACS Appl. Mater. Interfaces, 2012, 4, 2369.

12 D. Chateau, Q. Bellier, F. Chaput, P. Feneyrou, G. Berginc, O. Maury, C. Andraud and S. Parola, J. Mater. Chem. C, 2014, 2(26), 5105.

13 D. Chateau, A. Liotta, H. Lundén, F. Lerouge, F. Chaput, D. Krein, T. Cooper, C. Lopes, M. Lindgren and S. Parola, Adv. Funct. Mater., 2016, 26(33), 6005.

14 H. Lundén, A. Liotta, D. Chateau, F. Lerouge, F. Chaput, S. Parola, C. Brännlund, Z. Ghadyani, M. Kildemo, M. Lindgren and C. Lopes, J. Mater. Chem. C, 2015, 3, 1026.

15 H. Salmi, X. Allonas, C. Ley, A. Defoina and A. Aka, Polym. Chem., 2014, 5, 6577.

16 B. R. Harkness, K. Takeuchi and M. Tachikawa, Polym. Adv. Technol., 1999, 10, 669.

17 K. Suyama and M. Shirai, Prog. Polym. Sci., 2009, 34, 194.

18 H. Du and M. K. Boyd, Tetrahedron Lett., 2001, 42, 6645. 